\title{
La inversión extrangera directa en las principales economías de APEC y su relevancia para México
}

$\mathrm{D}$ esde el establecimiento (1989) del foro de Cooperación Económica para Asia Pacífico (APEC), los objetivos centrales que han movido a este organismo para su conformación y consolidación como grupo de la Cuenca del Pacífico son liberalizar y facilitar el comercio y la inversión en la región. Al mismo tiempo esto ha sido una de las metas primordiales de las 21 economías para lograr avances en el crecimiento económico.

Ha sido difícil ir cumpliendo esta meta debido a las disparidades de desarrollo de las economías que lo integran, ya que muchas están en vías de desarrollo y, en consecuencia, en algunos casos es necesario proteger a la industria en sectores estratégicos que aún no están preparados para la liberalización.

Otro de los puntos importantes en el proceso de regionalización abierta de APEC es que no debe existir trato discriminatorio para ninguna economía, sea o no miembro del organismo. Sin embargo, una de las ventajas de formar parte de APEC es que los acuerdos son voluntarios y esto disminuye el riesgo de afectar con la apertura a economías que aún no están preparadas para hacerlo. Existen opiniones al respecto que aseveran que con esta modalidad se puede caer en ineficiencias e, incluso, en procedimientos que puedan calificarse de trato discriminatorio a los países no miembros, como por ejemplo, los esquemas de promoción comercial del GATT, la visa especial de base regional o trato especial a agentes de negocios de APEC. Por lo tanto, lo ideal sería aplicar la liberalización obligatoria y, en las áreas que sea más conveniente, la liberalización voluntaria, como es el caso de las economías de reciente desarrollo o que están en vías de él. ${ }^{1}$

* Investigadora del Departamento de Estudios del Pacífico de la Universidad de Guadalajara.
La inversión extranjera directa (IED) trajo efectos positivos: creación de empleos, incremento en la producción, en los ingresos y exportaciones, y un mayor acceso a los avances tecnológicos, elementos indispensables para alcanzar el crecimiento económico. Los países se dan a la tarea de atraer la IED, creando la infraestructura necesaria para las crecientes aglomeraciones industriales, sobre todo en las actividades intensivas en tecnología.

Este trabajo trata sobre la importancia de la IED como fuente principal para alcanzar los objetivos de APEC, dado que la mayoría de las economías en el mundo se apoyan en ella para consolidar la industrialización. Una pieza clave de la estrategia de industrialización sostenible es que facilita la orientación del comercio hacia el exterior, una vez que ha entrado capital y una consecuente mejora en la tecnología. Actualmente, las empresas transnacionales (ETN) juegan un papel importante en la internacionalización de la economía, tanto en la dirección del comercio como en las corrientes de inversión, que han surgido como consecuencia de las privatizaciones y las fusiones de empresas. $^{2}$

Aunque no en todos los países la IED se ha incrementado de manera global por la creciente integración económica, las empresas han adoptado estrategias globales que ayudan a aumentar y facilitar la producción, logrando alianzas estratégicas con firmas extranjeras, lo cual facilita la obtención de insumos de otros países, así como la adquisición de nuevas tecnologías para mejorar el proceso de producción. La concentración de una industria o unas pocas industrias en una zona crea una densa red de competidores, compradores y proveedores, donde además se encuentran productos, recursos humanos, sofisticados servicios de crédito e instituciones de apoyo bien 
desarrolladas. Ejemplo de ello son el Silicon Valley en California, el Silicon Fen en Cambridge (Reino Unido), el Wireless Valley en Estocolmo, o el Zhong Guancum (un suburbio de Pekín), aglomeraciones industriales que tienen una clara ventaja para atraer IED de alto valor. ${ }^{3}$ Sin embargo, Hay países que pueden quedarse aún más marginados de la dinámica de la producción internacional porque no ofrecen las nuevas condiciones necesarias para atraer una IED de alta calidad, ya que no basta con liberalizar la economía para obtener los beneficios que prometen los países desarrollados que son los principales promotores de la liberalización, sino que deben tener la capacidad de crear y sostener aglomeraciones de empresas que se apoyen en las ventajas competitivas. En algunas industrias de alta tecnología, como la electrónica, quizá sea posible atraer la fase final del montaje a los países en desarrollo, basándose en la existencia de mano de obra semicalificada y eficiente en relación con su costo salarial y de instalaciones también eficientes de elaboración para la exportación. ${ }^{4}$

\section{Inversión extranjera directa en el mundo}

Uno de los sectores más favorecidos por la IED son los servicios, gracias a las políticas de liberalización de los últimos diez años, ya que los países desarrollados son los que participan con el mayor volumen de inversión y los que tienen mayor terciarización en la economía. En 1999 este sector concentraba más de la mitad del monto total acumulado de las entradas de IED en los países desarrollados, y alrededor de un tercio del monto acumulado de esas entradas en los países en desarrollo. La IED se concentra principalmente en la Unión Europea (UE), Estados Unidos y Japón: acapararon 71 por ciento de las entradas mundiales y 82 por ciento de las salidas en 2000. Por su parte, Asia (excluido Japón) solo alcanzó 11 y 7 por ciento, en entradas y salidas, respectivamente de IED. Cerca de 90 por ciento de las 100 mayores ETN no financieras del mundo por sus activos en el extranjero tienen su sede en la triada UE, Estados Unidos y Japón; más de la mitad de dichas empresas pertenecen a las industrias de material eléctrico y electrónico, a la industria automovilística, y a la de exportaciones y distribución de petróleo, las cuales sumaban en 1999, 12 por ciento de activos en el extranjero, 16 por ciento de las ventas y 15 por ciento del número de trabajadores de las más de 60000 ETN del mundo.

Más de 50 países (de los cuales 24 están en desarrollo) tienen cada uno un monto acumulado de entradas de IED que supera los 10000 millones de dólares; incomparable con los 17 países de hace quince años (siete de ellos en desarrollo). Por lo que se refiere a las salidas, el panorama es similar: el número de países, cuyo monto acumulado de salidas supera los 10000 millones de dólares, aumentó de 10 a 33 (y ahora incluye a doce países en desarrollo, en comparación con ocho en 1995) en el mismo período. Los treinta principales países receptores del mundo absorben 95 por ciento de las entradas mundiales totales de IED. Mientras que los 30 principales países inversores abarcan alrededor de 99 por ciento de las salidas mundiales de IED. ${ }^{5}$

\section{Inversión extranjera directa en APEC}

Del total de las IED de los países de APEC, Estados Unidos es el que absorbe un mayor porcentaje: 47 por ciento se dirige a ese país y 56 por ciento sale del mismo. China también es 
relevante con respecto a los demás países de APEC: 13 por ciento de la IED se dirige a esa nación, aunque sólo invierte 1.3 por ciento en el exterior. En Japón ocurre lo contrario: percibe 1.7 por ciento e invierte en otros países 14.5 por ciento. Canadá, aunque en menor proporción, también tiene importancia al respecto, ya que sus entradas y salidas ascienden a 7 y 8.8 por ciento respectivamente.

Japón vio disminuir en 2000 sus entradas, que alcanzaron los 8000 millones de dólares, en 36 por ciento en comparación con el año anterior, como consecuencia, en parte, de la prolongada reducción del crecimiento económico del país. Las salidas de IED de Japón repuntaron y subieron a 33000 millones de dólares, la cifra más alta en diez años. Otro país que sobresale por el monto de IED es Canadá, producto de grandes operaciones con empresas de Europa y Estados Unidos.

En los países en desarrollo de Asia, las entradas de IED alcanzaron la cifra récord de 143000 millones de dólares en 2000: Taiwán tuvo entradas por 64000 millones de dólares; Hong Kong pasó a ser el principal receptor de IED asiática debido a la recuperación de las turbulencias económicas del pasado reciente, y a una gran operación de fusión transfronteriza en el sector de las telecomunicaciones (por sí sola representó casi la tercera parte de las entradas totales de IED en el territorio), además de que se ha registrado un mayor movimiento de capitales y de que las ETN que planeaban hacer inversiones en China han estado invirtiendo fondos en Hong Kong, desde antes de la entrada de este país a la OMC. Las corrientes de IED hacia China, con 41000 millones de dólares, se mantuvieron estables. En los noventa en Indonesia decayeron notablemente las inversiones a raíz del estallido de la crisis financiera.

El comportamiento de las entradas de IED indica, a la vez, en qué medida los países receptores se van integrando a la economía internacional en vías de mundialización, y, directamente, cómo se reparten los beneficios de las IED.
Inversión extranjera directa de las economías de APEC en México

Aunque México no percibe los volúmenes de IED que los países de Asia-Pacífico, sí podemos decir que su incremento en la participación ha sido considerable, ya que de 41 mil millones de dólares que se acumularon en 1995, ascendió a 72 mil millones en 1999 (cuadro 1). La IED de México en otros países no es comparable con los países desarrollados; no obstante, ha manifestado un ligero incremento de 4 a 6.6 mil millones de dólares entre 1995 y 1999.

Estados Unidos es el principal inversor en México, aunque con una ligera reducción de 9 por ciento en 2001 con respecto al año anterior, manteniendo un promedio acumulado de 45 mil millones de dólares 1994-2001. Aunque manifestó un incremento de 46 por ciento en 1994, incrementó a 70 por ciento en 2001. La inversión de Canadá en México ocupa el segundo lugar en importancia, aunque en términos relativos la disminución ha sido muy notoria, ya que en 1994 representaba 7 por ciento que luego se redujo a 2.5 por ciento en 2001 . En lo que respecta a Japón, ocupa el tercer lugar en importancia; sin embargo, su disminución relativa ha sido muy notoria, pues aunque en 1999 ascendió a 10 por ciento, en 2001 cae a 1.4 por ciento. Corea y Singapur representan 4 y 2 por ciento, respectivamente; los demás países de APEC no son representativos en México (cuadro 2).

El 72.9 por ciento del total de sociedades con inversión foránea establecidas en México corresponden a los países de APEC, lo que equivale a 15572 empresas. El principal país de APEC que invierte en México es Estados Unidos, que participa con 82 por ciento del total, Canadá con 7.4 por ciento, Corea 3.7 por ciento, Japón 2.2 por ciento, China 1.1 por ciento, Chile 1.0 por ciento y los otros catorce países miembros participan con el 2.5 por ciento. Las empresas provenientes de APEC invierten principalmente en el sector servicios (profesionales, técnicos y especializados, servicios inmobiliarios y hoteles), los cuales registran 34.5 por ciento del total; el sector 
Cuadro 1

APEC: inversión extranjera directa

(miles de millones de dólares)

Acumulada

Flujo promedio anual

\begin{tabular}{lllllllll}
1985 & 1990 & 1995 & 1998 & & 1999 & $1990 / 1985$ & $1995 / 1990$ & $1999 / 1995$ \\
\hline
\end{tabular}

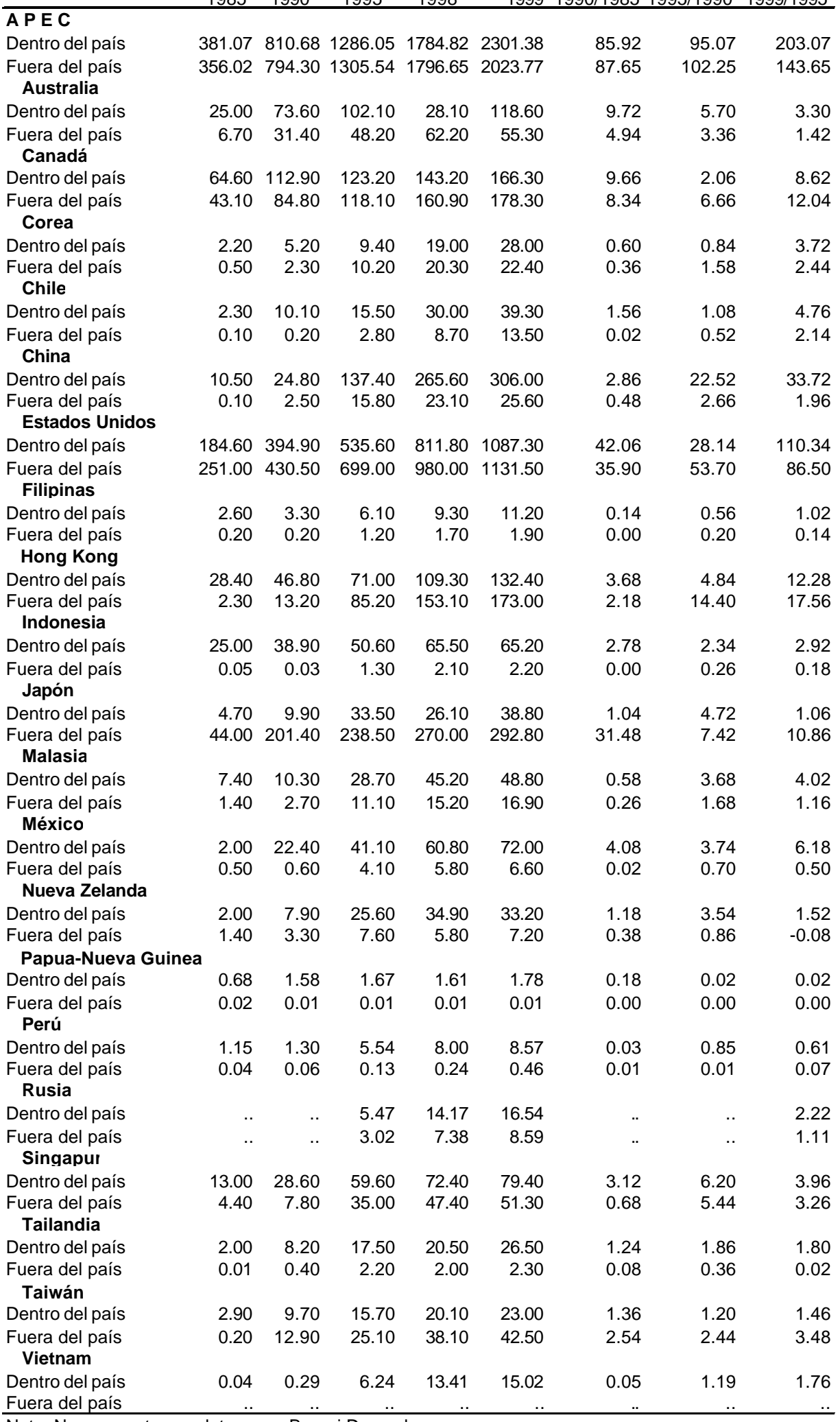

Nota. No se cuenta con datos para Brunei Darusalam.

Fuente: United Investment Conference on Trade and Development. World Investment Report 2000: cross-border mergers and acquisitions and development (Génova: UNCTAD 2000). 
Cuadro 2

México: IED de los países de APEC, 1994-2001

(miles de dólares y porcentajes)

\begin{tabular}{|c|c|c|c|c|c|c|c|c|c|}
\hline & $\begin{array}{c}\text { Acumulado } \\
\text { (miles de dólares) }\end{array}$ & & & & rcer & tajes & & & \\
\hline & $1994-2001$ & 1994 & 1995 & 1996 & 1997 & 1998 & 1999 & 2000 & 2001 \\
\hline$\overline{\text { IED total }}$ & $72,092,644$ & 100 & 100 & 100 & 100 & 100 & 100 & 100 & 100 \\
\hline A P E C & $52,600,966$ & 59.6 & 71.2 & 78.0 & 68.5 & 71.6 & 72.0 & 88.1 & 74.9 \\
\hline Estados Unidos & $45,461,179$ & 46.3 & 65.5 & 67.4 & 61.3 & 66.1 & 55.5 & 79.1 & 70.0 \\
\hline Canadá & $3,081,254$ & 7.0 & 2.1 & 6.7 & 1.9 & 2.4 & 5.0 & 4.8 & 2.5 \\
\hline Japón & $3,025,298$ & 6.0 & 1.9 & 1.8 & 3.0 & 1.3 & 10.3 & 3.2 & 1.4 \\
\hline Corea & 513,540 & 0.1 & 1.3 & 1.1 & 1.6 & 0.7 & 0.4 & 0.1 & 0.3 \\
\hline Singapur & 256,449 & 0.0 & 0.2 & 0.4 & 0.2 & 0.5 & 0.5 & 0.6 & 0.4 \\
\hline Taiwán & 68,619 & 0.0 & 0.0 & 0.0 & 0.1 & 0.4 & 0.2 & 0.0 & 0.2 \\
\hline Chile & 66,369 & 0.0 & 0.1 & 0.0 & 0.3 & 0.1 & 0.0 & 0.0 & 0.0 \\
\hline Australia & 43,224 & 0.2 & 0.0 & 0.1 & 0.0 & 0.0 & 0.1 & 0.1 & 0.0 \\
\hline China & 38,215 & 0.0 & 0.1 & 0.1 & 0.0 & 0.1 & 0.0 & 0.0 & 0.0 \\
\hline Hong Kong & 21,668 & 0.0 & 0.0 & 0.1 & 0.0 & 0.1 & 0.0 & 0.0 & 0.0 \\
\hline Tailandia & 17,137 & 0.0 & 0.0 & 0.2 & 0.0 & 0.0 & 0.0 & 0.0 & 0.0 \\
\hline Perú & 4,819 & 0.0 & 0.0 & 0.0 & 0.0 & 0.0 & 0.0 & 0.0 & 0.0 \\
\hline Rusia & 1,469 & 0.0 & 0.0 & 0.0 & 0.0 & 0.0 & 0.0 & 0.0 & 0.0 \\
\hline Filipinas & 621 & 0.0 & 0.1 & 0.0 & 0.0 & -0.1 & 0.0 & 0.0 & 0.0 \\
\hline Malasia & 461 & 0.0 & 0.0 & 0.0 & 0.0 & 0.0 & 0.0 & 0.0 & 0.0 \\
\hline Indonesia & 371 & 0.0 & 0.0 & 0.0 & 0.0 & 0.0 & 0.0 & 0.0 & 0.0 \\
\hline Nueva Zelanda & 167 & 0.0 & 0.0 & 0.0 & 0.0 & 0.0 & 0.0 & 0.0 & 0.0 \\
\hline Vietnam & 108 & 0.0 & 0.0 & 0.0 & 0.0 & 0.0 & 0.0 & 0.0 & 0.0 \\
\hline Brunei Darusalam & 0 & 0.0 & 0.0 & 0.0 & 0.0 & 0.0 & 0.0 & 0.0 & 0.0 \\
\hline Papua-Nueva Guinea & 0 & 0.0 & 0.0 & 0.0 & 0.0 & 0.0 & 0.0 & 0.0 & 0.0 \\
\hline
\end{tabular}

* Para el período 1994-1998, la inversión extranjera directa (IED) se integra con los montos notificados

al Registro Nacional de Inversiones Extranjeras (RNIE), más las importaciones de activo fijo realizadas

por sociedades maquiladoras. A partir de 1999 se incluyen además los conceptos de nuevas inversiones,

reinversión de utilidades y cuentas entre compañías que se han notificado al RNIE.

Cabe mencionar que esta información no incluye todas las aportaciones realizadas por los

inversionistas de la APEC, debido a que no se consideraron las inversiones que realizan las

empresas de ese bloque mediante sus filiales en otros países, pues el país de la inversión se clasifica

con base en la nacionalidad del inversionista extranjero y no respecto del origen primario de los recursos.

Notas:

1. Enero-marzo.

2 Notificada al 31 de marzo de 2001.

Fuente: Secretaría de Economía. Subsecretaría de Negociaciones Comerciales Internacionales,

Dirección General de Inversión Extranjera, Inversión en México de los países miembros de la APEC, marzo 2001.

manufacturero, 33.4 por ciento; el comercio 23.5 por ciento; minería y extracción 3 por ciento; construcción 2.1 por ciento, y el resto en transporte y comunicaciones, sector agropecuario, electricidad y agua, ${ }^{6}$

\section{Comentarios finales}

La orientación de los flujos de inversión está determinada por las ETN que proceden de los países desarrollados, y en los cuales 
encontramos fuertes compradores y vendedores, ya que cuentan con tecnología de punta, con productos innovadores y modernos métodos de organización. Sin embargo, debido a la competencia que enfrentan en esos países, las ETN buscan condiciones propicias en los países en desarrollo con la finalidad de expandirse y obtener mejores ganancias. Sin embargo, no todas las vinculaciones son benéficas para las economías receptoras, cuyas legislaciones no propician la transferencia de tecnología de punta, por lo que es de esperarse que los flujos de inversión se den en un solo sentido, ya que la capacidad de inversión de los países en desarrollo es muy baja (cuadro 1).

\section{Notas}

1 Yoshi Kodama. Asia Pacific Economic Integration and the GATT/WTO Regime, International Economic Development, Law Series, Kluwer Law/International, 2000, pp. 246-258.

2 UNCTAD. Informe sobre las inversiones en el mundo, 2001.

3 Ibid, p 27.

4 Ibid, p 26.

5 Ibid, p 9.

6 Secretaría de Economía. Subsecretaría de Negociaciones Comerciales Internacionales, Dirección General de Inversión Extranjera, Inversión en México de los países miembros de APEC, marzo de 2001. T: 